\title{
Effect of Nigella sativa Oil on Female Rats Exposed to Lead
}

\author{
Majdah H Al-Massari*, Isam M Abu Zeid, Ihsan Ullah and Naser A \\ Alkenani \\ Department of Biological Sciences, Faculty of Sciences, King Abdulaziz University, \\ Saudi Arabia \\ *Corresponding Author: Majdah H Al-Massari, Department of Biological Sciences, \\ Faculty of Sciences, King Abdulaziz University, Saudi Arabia.
}

Received: January 24, 2020

Published: January 31, 2020

(C) All rights are reserved by Majdah $\mathbf{H}$

Al-Massari., et al.

DOI: $10.31080 /$ ASMS.2020.04.0550

\begin{abstract}
Environmental pollution is among the major issues the world is facing today. Lead (Pb) contamination even, at a small amount may cause serious damage to vital organs in the body such as liver. On the other hand, medicinal plants have been used for many centuries to cure diseases, especially the black seed (Nigella sativa) (NS). Nigella sativa oil (NSO) is a great source of antioxidants and fatty acids. The objective of this research is to assess the potential use of NSO as the possible protective agent in female rats exposed to $\mathrm{Pb}$ using several biochemical parameters, besides the histological changes induced by $\mathrm{Pb}$ in liver. In this study, 40 female rats were equally allocated into 4 groups. Rats of the first group (G1) were served as normal controls. Rats of the second group (G2) were orally ingested every two days with a single dose of $\mathrm{Pb}$ acetate $(150 \mathrm{mg} / \mathrm{kg} / \mathrm{body}$ weight $)$ for a period of 6 weeks. Rats of the third group were exposed to $\mathrm{Pb}$ acetate similar to group 2 and Nigella sativa oil ( $(700 \mathrm{mg} / \mathrm{kg} /$ day). Rats of the fourth group were administered Nigella sativa oil. Results showed that oral administration of $\mathrm{Pb}$ acetate exhibited highly significant increase in the levels of liver function enzymes. Histological examinations of liver sections from rats exposed to only $\mathrm{Pb}$ acetate showed severe alterations. This study showed that Nigella sativa oil attenuated the biochemical and histological changes induced by Pb intoxication.
\end{abstract}

Keywords: Environmental Pollution; Heavy Metals; Pb; Toxicity; Nigella Sativa; Nigella Sativa Oil

\section{Abbreviations}

NSO: Nigella Sativa Oil; ANOVA: Analysis Of Variance; MM: Millimolar; SD: Standard Deviation; ALT: Alanine Amino Transferase; AST: Aminotransferas; ALP: Alkaline Phosphatase; GGT: Gamma Glutamyl Transferase; GI: Group I; G2: Group 2.

\section{Introduction}

Pollution means the addition of contaminants into the natural environment, causing damage and causing disturbance in the ecosystem [1]. These pollutants are either exogenous to the environment or natural substances but have exceeded accepted levels [2]. Pollution encompasses a wider dimensions including, chemical pollutants [3], thermal pollution [4], soil pollution [5], and biologi- cal and non-biological industrial and domestic pollution [6]. Various form of the pollution affects the human being and it is among the worse problems the globe is facing today [7].

All heavy metals are toxic at even very small concentration, they enter into the living tissues through several ways either by inhalation, eating, drinking, soil and manual handling [8]. Some heavy metals such as iron, magnesium and zinc are very important at trace amount for normal body physiology [9]. Exposure to toxins in general and to heavy metals Lead to many health problems such as disorders of the nervous system, immune disorders, cancers, kidney and liver damage and disruption of endocrine work [10]. In particular, $\mathrm{Pb}$ is a soft heavy metal, elastic metal element that is 
extensible, white and bluish-gray, which is mostly extracted from the earth's crust. $\mathrm{Pb}$ toxicity occurs when build up in the body, often months or years. Even small amounts of $\mathrm{Pb}$ can cause serious health problems. Children under age of 6 years are more likely to have $\mathrm{Pb}$ poisoning, which can severely affect mental and physical development [11]. In the case of very high levels, $\mathrm{Pb}$ poisoning can cause death. It is difficult to detect, even people who are healthy may have high levels of $\mathrm{Pb}$ in their blood. Usually signs and symptoms do not appear until the accumulation of dangerous amounts is ingested [11].

Since $\mathrm{Pb}$ affects the vital organs of the body such as the liver and kidney, it therefore works on the precise impact on the cells in the body, and here we investigated the effect of $\mathrm{Pb}$ specifically on the vital organs. Sources of exposure to $\mathrm{Pb}$ include: industrial processes, food and drinking water, smoking [12]. Moreover, $\mathrm{Pb}$ poisoning occurs from several sources such as: paint houses, faucets, toys, car batteries, exhaust cars and plumbing pipes [13].

$\mathrm{Pb}$ toxicity in cells is shown by oxidative stress, which is caused by the imbalance between the production of free radical's (ROS) and antioxidants that work primarily on detoxification. The most prominent of these is glutathione (GSH), which is found mainly in the cell to protect it from oxidation with free radicals such as $\mathrm{H} 2 \mathrm{O} 2$ resulting from the effect of $\mathrm{Pb}$ accumulation on the cell. This accumulation increases the production of ROS and decreases GSH, thus increasing the toxicity in the cell, Bring to the appearance of structural damage in cells, proteins, nucleic acids, membranes, and fat. Thus, cellular tension occurs, which does not allow the cell to perform its main functions due to the breakdown of many of its components depending on the high toxicity [13].

Herbal medicine has been known since ancient times for their therapeutic and preventive role in curing many diseases. Hence, the seeds, leaves, roots and fruits were used for the treatment of diseases and extraction of many medicinal drugs until the present age [14]. Nigella sativa or black seeds ( $N$. sativa) were the most important medicinal plants and most commonly used because of their immune role in the treatment of toxins $[15,16]$ and many diseases such as cancer [17], heart disease [18,19] and neurological diseases $[20,21]$. It is annual herb, about $20-90 \mathrm{~cm}$ long, with a straight erect stalk, delicate deep-cut leaves, blue-to-gray flowers, horns and serrated seeds [22].
The N. sativa was originated in the Mediterranean region and then spread to middle east like; Saudi Arabia, Iraq and sham countries (Syria, Palestine, Lebanon), turkey, Iran, North Africa such as (Egypt, Morocco, Algeria, Tunisia), parts of South Asian such as India, China. Also known in southern Europe and America [23]. The oil of the $N$. sativa commonly known as black cumin oil or black coriander oil, used as medicine for treatment of various ailments throughout the world [24]. The oil has antioxidants, anti-inflammatory and anticancer activities [23]. The present study aimed to investigate the protective effect of Nigella sativa oil on lead-intoxicated female rats.

\section{Materials and Methods}

\section{Animals}

Forty female Wistar rats (120 - 150g) were supplied by Mansour Scientific Foundation for Research and Development, King Abdulaziz University, Jeddah, Saudi Arabia. The animals were kept under the condition as described by Mohamadin., et al [26].

\section{Nigella sativa oil (NSO)}

High quality Nigella sativa oil (NSO) was obtained from Adnan Subgha Centre for Natural Herbs Jeddah, Saudi Arabia. The oil was stored in the laboratory until use.

\section{Experimental procedure}

Four groups of the rats were randomly made having 10 individuals per group ( $n=10$ /group). The NSO was administered orally as treatment for six weeks. The normal and $\mathrm{Pb}$-intoxicated groups were as follows:

1. Were untreated and served as control.

2. Were orally administered a single dose of $\mathrm{Pb}$ acetate $(150 \mathrm{mg} /$ $\mathrm{kg} /$ body weight) day after day.

3. Were orally administered a single dose of $\mathrm{Pb}$ acetate $(150 \mathrm{mg} /$ $\mathrm{kg} /$ body weight) day after day plus Nigella sativa oil (700mg/ $\mathrm{kg} /$ day).

4. Were orally supplemented with Nigella sativa oil $(700 \mathrm{mg} / \mathrm{kg} /$ day).

\section{Samples collection}

Blood sampling

At the end of the gestation period, the rats were anesthetized 
with ethyl ether. Blood samples were collected from orbital plexus veins in taps other than heparin, and then extracted for $15 \mathrm{~min}$ at 3,000 rpm to separate serum. Blood was then collected, frozen at $-80{ }^{\circ} \mathrm{C}$ and stored until used for biochemical analysis. Serum samples were used to determine the level of liver function testing (ALT, AST, ALP, GGT, total bilirubin). All biochemical parameters were measured by automatic analyzers analyzer using their specified kits.

\section{Histological analysis}

The stored liver samples were processed in a formalin tissue processor. Treatment consists of two steps, preliminary injection and dehydration. Add tissue to the tissue immersion in 10 hours buffer the format for 48 hours, then remove the fixative in distilled water for 30 minutes. Subsequently, water degradation was performed by running the tissues by alcohol classification (70\%, 90\% and $100 \%$ ). The tissues were initially exposed to $70 \%$ alcohol for 120 minutes, then $90 \%$ alcohol for 90 minutes, then two cycles of absolute alcohol, each exposed for one hour. Subsequent dehydration eliminated the sample in several changes to xylene. It contains $50 \%$ alcohol and $50 \%$ xylene in a mixture of submerged tissues for one hour, followed by pure xylene for an hour and a half. The samples were then stained with molten paraffin wax, and then added and withheld. Paraffin sections ( 4 - $5 \mathrm{mM}$ ) were contaminated with hematoxylin and eosin [25]. Stained sections were inspected for any pathologic changes.

\section{Statistical analysis}

one- way ANOVA was applied to analyse the data and data was expressed as mean \pm SD. Significant level set at $\mathrm{p} \leq 0.05$. The statistical analysis was performed using SPSS software for windows, version 22, Armonk, NY. Data are presented using GraphPad Prism version.

\section{Results}

\section{Clinical signs}

Female rats of control group G1 and NSO group G4 did not reveal any clinical symptoms throughout study period. G2 which given $\mathrm{Pb}$ acetate appeared toxicity symptoms like weakness, lethargy and slow movement. While the $\mathrm{Pb}$ and oil treatment G3 did not notice any changes in movement, colour, or other behavioural changes throughout the duration of the experiment, except some rats that showed lethargy and slow movement sometimes, but as general the symptoms of $\mathrm{Pb}$ poisoning were not observed significantly throughout the treatment.

\section{Biochemical analysis of liver functions}

The results of the activities of the enzymes alanine aminotransferase (ALT), aspartate aminotransferase (AST), alkaline phosphatase (ALP), gamma glutamyl Transferase (GGT) and total bilirubin in different groups studied are presented in Figures (1 to 5 ) and Table 1 . In the control group (GI), the mean values \pm SE of the enzymes ALT, AST, ALP, GGT and total bilirubin were $(134 \pm 1.3,19 \pm$ $1.2,65 \pm 3.2,22 \pm 2.2 \mathrm{IU} / \mathrm{L})$ and $(0.58 \pm 0.07 \mathrm{mg} / \mathrm{dl})$ respectively.

While in $\mathrm{Pb}$ treated group (G2) the mean values $\pm \mathrm{SE}$ of the enzymes ALT, AST, ALP, GGT and total bilirubin were significantly increased $(\mathrm{P}<0.05)\left(400 \pm 2.8^{*}, 65 \pm 4.6 *, 193 \pm 5.1^{*}, 107 \pm 4.6^{*}\right.$ $\mathrm{IU} / \mathrm{L})\left(1.49 \pm 0.11^{*} \mathrm{mg} / \mathrm{dl}\right)$ respectively when compared with GI. In $\mathrm{Pb}$ treated $+\mathrm{NSO}$ (G3) the mean values $\pm \mathrm{SE}$ of the enzymes ALT, AST, ALP, GGT and total bilirubin were $(241 \pm 2.0 *$ \#, $38 \pm 1.7 * \#$, $103 \pm 5.4 * \#, 66 \pm 2.5$ \#*IU/L) and (0.95 $\left.\pm 0.09^{* * *} \# \mathrm{mg} / \mathrm{dl}\right)$ respectively were slightly higher when compared with GI. And in NSO treated group (G4) the mean values \pm SE of the enzymes ALT, AST, ALP, GGT and total bilirubin $(138 \pm 0.8,21 \pm 2.3,68 \pm 4.9,22 \pm$ $2.3 \mathrm{IU} / \mathrm{L})$ and $(0.62 \pm 0.06 \mathrm{mg} / \mathrm{dl})$ respectively were slightly close when compared with (G1).

On other hand, the values in $\mathrm{Pb}$ acetate treated group (G2), were increased for (ALT, AST, ALP, GGT and total bilirubin) ( $400 \pm 2.8^{*}, 65$ $\left.\pm 4.6^{*}, 193 \pm 5.1^{*}, 107 \pm 4.6^{*} 1.49 \pm 0.11^{*} \mathrm{IU} / \mathrm{L}\right)$ and $\left(1.49 \pm 0.11^{*}\right.$ $\mathrm{mg} / \mathrm{dl}$ ) respectively when compared with $\mathrm{Pb}$ treated + NSO (G3) $(241 \pm 2.0 * \#, 38 \pm 1.7 * \#, 103 \pm 5.4 * \#, 66 \pm 2.5$ \#*IU/L) and (0.95

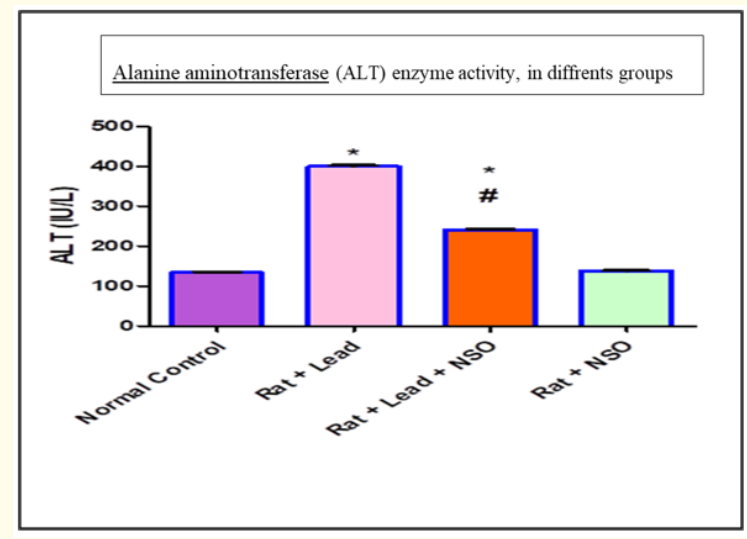

Figure 1: Mean values \pm SE of Alanine aminotransferase (ALT) enzyme activity, in control group (G1), Pb treated group (G2), Pb + NSO treated group (G3), NSO treated group (G4). *P $\leq 0.001$ from control, \#P $\leq 0.001$ from $\mathrm{Pb}$. 


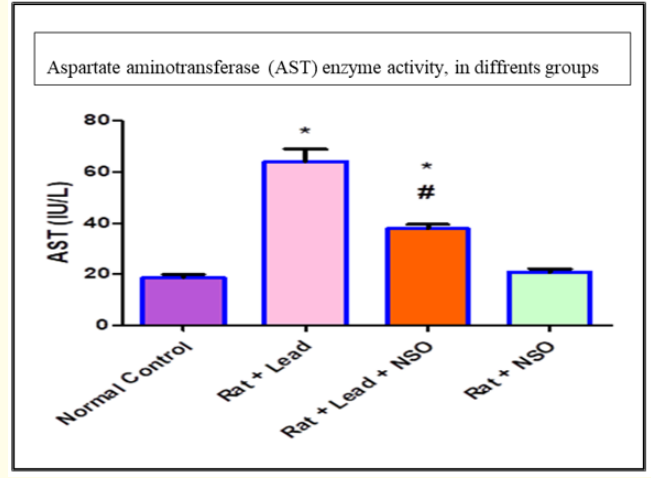

Figure 2: Mean values \pm SE of Aspartate aminotransferase (AST) enzyme activity, in control group (G1), Pb treated group (G2), Pb + NSO treated group (G3), NSO treated group (G4). *P $\leq$ 0.001 from control, \#P $\leq 0.001$ from $\mathrm{Pb}$.

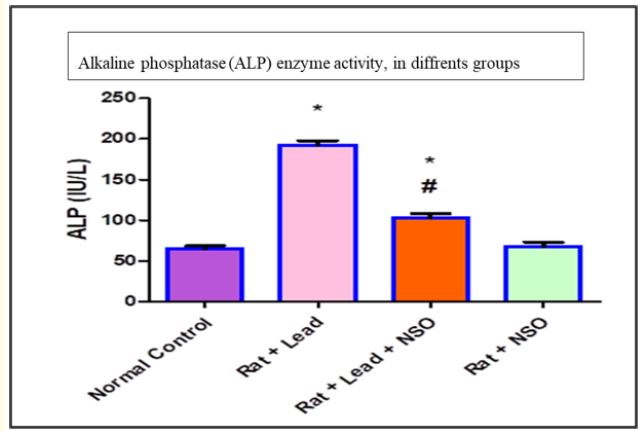

Figure 3: Mean values \pm SE of Alkaline phosphatase (ALP) enzyme activity, in control group (G1), Pb treated group (G2), $\mathrm{Pb}$ + NSO treated group (G3), NSO treated group (G4). ${ }^{*} \mathrm{P} \leq 0.001$ from control, $\# \mathrm{P} \leq 0.001$ from $\mathrm{Pb}$.

$\pm 0.09^{* * *} \# \mathrm{mg} / \mathrm{dl}$ ) respectively.

Histological analysis

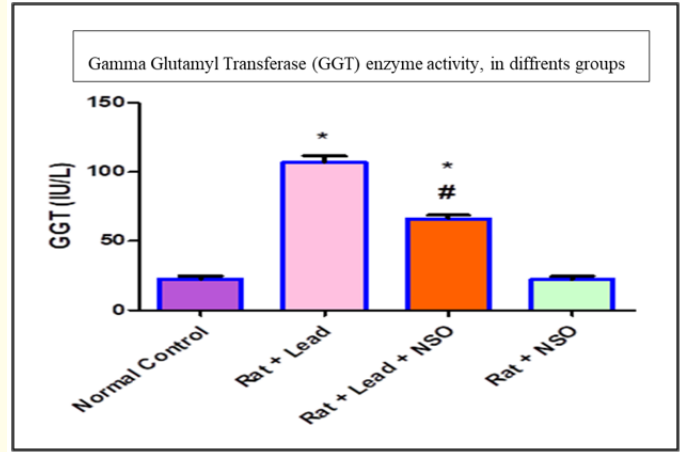

Figure 4: Mean values \pm SE of Gamma Glutamyl Transferase (GGT) enzyme activity, in control group (G1), Pb treated group (G2), Pb + NSO treated group (G3), NSO treated group (G4). *P $\leq$ 0.001 from control, $\# \mathrm{P} \leq 0.001$ from $\mathrm{Pb}$.

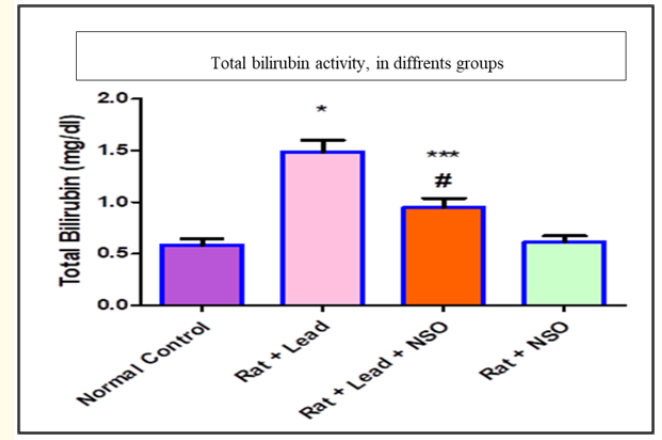

Figure 5: Mean values \pm SE of total bilirubin activity, in control group (G1), Pb treated group (G2), Pb + NSO treated group (G3), NSO treated group (G4). ${ }^{*} \mathrm{P} \leq 0.001$ from control. ${ }^{* *} \mathrm{P} \leq 0.05$ from control, $\# \mathrm{P} \leq 0.001$ from $\mathrm{Pb}$.

Light microscope observations in the control group (G1)

Liver tissue in the control group (GI) revealed a normal liver composition. Figures $6 \mathrm{~A}$ and $6 \mathrm{~B}$ showed the liver lobules, which

\begin{tabular}{|l|c|c|c|c|c|}
\hline Treatment & ALT (IU/L) & AST (IU/L) & ALP (IU/L) & GGT (IU/L) & Total Bilirubin (mg/dl) \\
\hline Normal Control & $134 \pm 1.3$ & $19 \pm 1.2$ & $65 \pm 3.2$ & $22 \pm 2.2$ & $0.58 \pm 0.07$ \\
\hline Rat + Pb & $400 \pm 2 . .^{*}$ & $65 \pm 4.6^{*}$ & $193 \pm 5 \cdot 1^{*}$ & $107 \pm 4.6^{*}$ & $1.49 \pm 0.11^{*}$ \\
\hline Rat + Pb + NSO & $241 \pm 2.0^{* \#}$ & $38 \pm 1.7^{* \#}$ & $103 \pm 5.4^{* \#}$ & $66 \pm 2.5^{\#^{*}}$ & $0.95 \pm 0.09^{* * *}$ \\
\hline Rat + NSO & $138 \pm 0.8$ & $21 \pm 2.3$ & $68 \pm 4.9$ & $22 \pm 2.3$ & $0.62 \pm 0.06$ \\
\hline
\end{tabular}

Table 1: Effect of activated NSO on the serum levels of Aspartate aminotransferase (AST), Alkaline phosphatase (ALP) and Alanine aminotransferase (ALT), Gamma-glutamyl transferase (GGT) and Total Bilirubin in Pb acetate-treated in female rats.

${ }^{*} \mathrm{P} \leq 0.001$ from control, ${ }^{* *} \mathrm{P} \leq 0.01$ from control, $\# \mathrm{P} \leq 0.001$ from $\mathrm{Pb}$, \#\#\# $\mathrm{P} \leq 0.05$ from $\mathrm{Pb}$. 
are polygonal units that display plates of epithelial cells called hepatocytes radiating from central vein (CV). The liver cells were comprised of an interconnected plate such as wall brick and slab around the central vein. The central vein of each lobule was indicated by its location in the center of each lobule. Specialized cells known as Kufr (K) cells were easily identified using $\mathrm{H}$ and $\mathrm{E}$ stains and were found between endothelial sinus cells.

\section{Light microscopy observations in $\mathrm{Pb}$ acetate group (G2)}

The liver tissue records in the Pb group (G2) revealed that there were some changes in the liver cells such as cytoplasmic void with the larynx nuclei. In some cells, chromatin was deposited in the

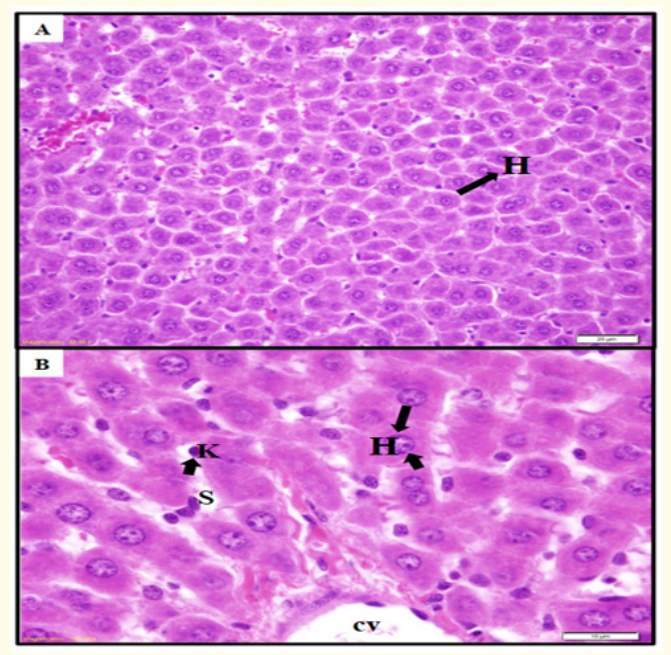

Figure 6: (A) Light microscopy micrograph of liver tissue from control group showing normal architecture, normal hepatocytes (H). (B) with central nuclei, which forms hepatic cords radiating around central vein (CV), with blood sinusoids (S) with normal Kupffer cells (K). (a) (H and E stain X 40), (b) (H and E stain X 60).

nuclear envelope and in some cells there was degeneration and necrosis. In addition, Koffer $(\mathrm{K})$ cell numbers showed an increase (Figures 7A and 7B).

Light microscopy observations of liver in Pb and NSO group (G3)

Examination of the liver in $\mathrm{Pb}$ acetate and NSO (G3) group revealed that liver tissue appeared in the normal control group, where the liver cords appear normal and circulate around the cen-

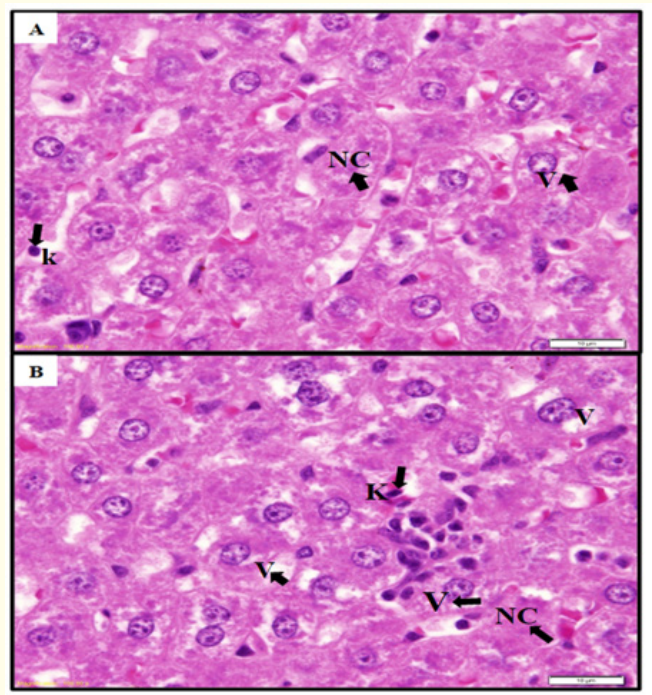

Figure 7: (A) Light microscopy micrograph of normal liver tissue (B) Micrograph from $\mathrm{Pb}$ treated group showing changes in the hepatocytes, which appeared in vacuolation (V) of cytoplasm and necrosis (NC) in some cells and increasing in size and numbers of Kupffer cells (K). (a) (H and E stain X 100), (b)

(H and E stain X 100.

tral vein. do. Liver cells were usually shown with round nuclei and were mainly found in the cytoplasm, but to some extent there were some liver cells, including the cytoplasm that remained in space and weak stained nuclei, sinusoids in the blood and the Kupffer cells were shown as normal (Figure 8A and 8B).

\section{Light microscopy observations in NSO group (G4)}

The liver of the NSO (G4) group revealed a normal structure similar to that in the control group (GI), where the liver cells, which appeared normal with the nuclei in the center, rounded, and that the sinusoids (S) arranged in between the hepatic cords. Kupffer cells were purified in their normal number (K) (Figs 9A and 9B).

\section{Discussion}

When $\mathrm{Pb}$ accumulates in the body, it is poisoned for months or years later. Even a small amount of lead can cause serious health problems. Children are more likely to get poisoned, which can severely affect mental and physical development. At very high levels, $\mathrm{Pb}$ poisoning can lead to death [26]. N. sativa is an important 


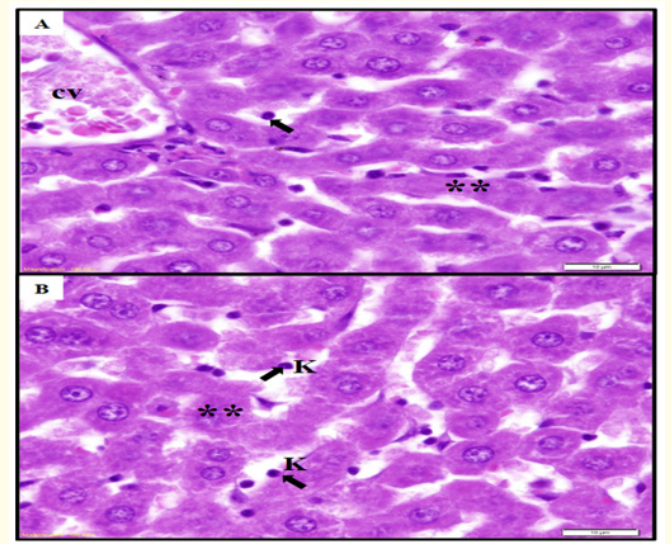

Figure 8: (A) light microscopy micrograph of liver tissue from $\mathrm{Pb}$ and NSO group showing some improvement of the hepatocytes, which appeared normally in the hepatic cords, around the central vein (CV). (B) Some cells still showing changes $\left.{ }^{* *}\right)$ in the form of necrosis and increasing in Kupffer cells (K). (a) (H and E stain X 100), (b) (H and E stain X 100).

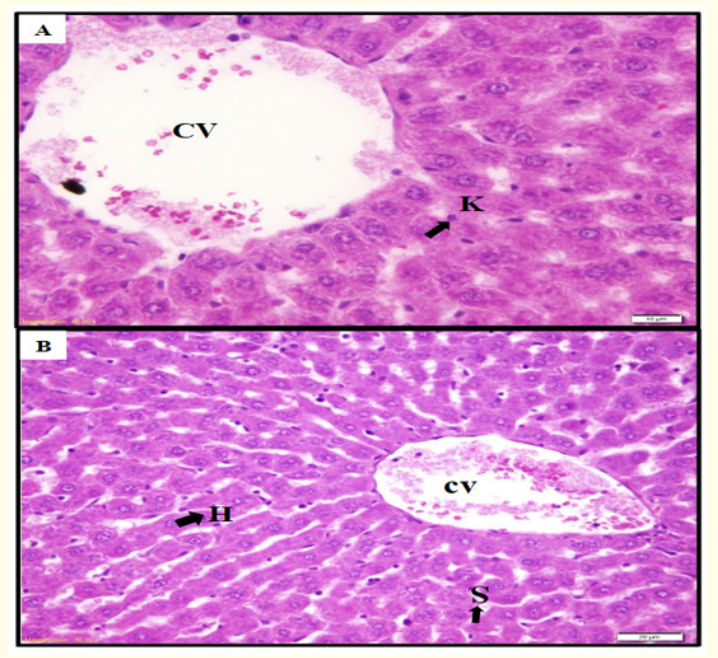

Figure 9: (A) Light microscopy micrograph of liver tissue from NSO administered group showing improvement of hepatocytes $(\mathrm{H})$ with central nuclei which arranged in hepatic cords around central vein (CV). (B) Normal number of Kupffer cells (K), and normal sinusoids (S). (a) (H and E stain X 60), (b)

(H and E stain X 40. medicinal plants, commonly known as blackhead or black coriander which belong to Ranunculaceae family. $N$. sativa has greater medicinal importance in Islamic medicine, everything except death is known as cure. The results of this study showed that $\mathrm{Pb}$ acetate caused biochemical alterations, toxicity and histological changes in the liver. The levels of the enzymes e.g., ALT, AST, GGT, and ALP activities were increased in the present study, after administration of $\mathrm{Pb}$ acetate then decreased approximately to the control level when administering with NSO. The results could be due to the protective effect of NSO. Research carried out by Randhawa., et al. [27] showed the protective impact of thymoquinone (TQ), the main active ingredient in volatile $N$. sativa seed oil, against $\mathrm{Pb}$-induced liver injury. In a similar study, Ahmed and Hassanein [29], studied the cardio-protective effect of $N$. sativa oil (NSO) on $\mathrm{Pb}$ induced cardio toxicity. The authors found that the $\mathrm{Pb}$ intake induced a significant increase $(\mathrm{p}<0.001)$ in malondialdehyde (MDA) in treated group as compared to control. It has been reported that the protective role of $N$. sativa in several natural and chemical toxins, including $\mathrm{Pb}$, is in line with current research that causes AST, urea, creatinine, total cholesterol and significant increase [10,29].

Morphological modifications in the liver that follow acute $\mathrm{Pb}$ exposure rely on the amount and moment at which these modifications are observed and may differ from dilation of the rough endoplasmic reticulum with loss of ribosomes to hepatocellular necrosis [17]. In addition, liver is the largest gland in the human body and performs many functions including glycogen storage, blood glucose release, and biotransformation process. The results of the histopathological examination showed that administration of $\mathrm{Pb}$, to female rats resulted in a clear effect in hepatocytes $(\mathrm{H})$ with the appearance of a vacuolation (V) in the cytoplasm, an increase in the size and number of Kupffer (K) cells, and necrosis (NC) in many cells. The present results showed that administration of $N$. sativa oil to $\mathrm{Pb}$-intoxicated rats significantly repaired the damaged areas which were affected due to Pb toxicity. Similarly, Radwan and Mohamed [30] explored the modulatory effect of $N$. sativa on the therapeutic potential of mesenchymal stem cells (MSCs) against irradiation-induced liver damage in rats. The authors observed that combined NSO/MSCs therapy provided more beneficial tissue repair comparable to MSCs alone [30]. 


\section{Conclusion}

The present study concerned with toxicity of the $\mathrm{Pb}$, which cause severe damage to the liver structure and functions. The treatment of the liver injured by $\mathrm{Pb}$ toxicity was significantly decreased by the administration of $N$. Sativa oil. The enzymatic function in the liver was also restored to the normalancy and showed the recovery of the damaged liver. The treatment significantly repaired the damaged areas which were affected due to $\mathrm{Pb}$ toxicity. In short, the $\mathrm{N}$. Sativa oil showed a great medicinal effect to recover the damage liver and could be used as treatment against the $\mathrm{Pb}$ toxicity.

\section{Bibliography}

1. Nagle JC., et al. "The Idea of Pollution". UC Davis Law Review 1-78.

2. Oke SA. "On the environmental pollution problem: A review". Journal of Environmental Engineering and Landscape Management 12.3 (2004): 108-113.

3. Jariwala HJ., et al. "Noise Pollution and Human Health: A Review". Noise and Air Pollution 3 (2017): 1-4.

4. Germani AR., et al. Air Pollution and Migration in Italy: An Empirical Investigation at Provincial Level. 14 (2018): 26-31.

5. Roychoudhury N and Exploration RE. "Soil pollution: Causes, effects and control Soil pollution: Causes, effects and control". Van Sangyan 3 (2016):1-14.

6. Mollazadeh $\mathrm{H}$ and Hosseinzadeh $\mathrm{H}$. "The protective effect of Nigella sativa against liver injury: A review". Iranian Journal of Basic Medical Sciences 17.12 (2014): 958-966.

7. Pourbakhsh H., et al. "Effect of nigella sativa fixed oil on ethanol toxicity in rats". Iranian Journal of Basic Medical Sciences 17.12 (2014):1020-1031.

8. Singh R., et al. "Heavy metals and living systems: An overview". Indian Journal of Pharmacology 43.3 (2011): 246-253.

9. Tchounwou PB., et al. "Heavy Metals Toxicity and the Environment”. In Molecular, Clinical and Environmental Toxicology (2012): 133-164.

10. Wani AL., et al. Pb toxicity: a review 8.2 (2015): 55-64.

11. Narayana $\mathrm{K}$ and Al-Bader M. "Ultrastructural and DNA damaging effects of $\mathrm{Pb}$ nitrate in the liver". Experimental and Toxicologic Pathology 63.1-2 (2011): 43-51.
12. Brochin R., et al. The Cellular Effect of $\mathrm{Pb}$ Poisoning and Its Clinical Picture. 5.2 (2008): 34-42.

13. Gillis BS., et al. Analysis of Pb toxicity in human cells 13.1 (2012):1-6.

14. Al-Attar., et al. "Preventive effects of black seed (Nigella sativa) extract on Sprague Dawley rats exposed to diazinon". Australian Journal of Basic and Applied Sciences 4.5 (2010): 957-968.

15. Abdelmeguid NE., et al. "Effects of Nigella sativa and thymoquinone on biochemical and subcellular changes in pancreatic $\beta$-cells of streptozotocin-induced diabetic rats". Journal of Diabetes 2.4 (2010): 256-266.

16. Mohamadin AM., et al. "Protective effects of Nigella sativa oil on propoxur-induced toxicity and oxidative stress in rat brain regions". Pesticide Biochemistry and Physiology 98.1 (2010): 128-134.

17. Rahmani AH., et al. "Therapeutic implications of black seed and its constituent thymoquinone in the prevention of cancer through inactivation and activation of molecular pathways". Evidence-based Complementary and Alternative Medicine (2014).

18. Salem ML and Hossain MS. "Protective effect of black seed oil from Nigella sativa against murine cytomegalovirus infection". International Journal of Immunopharmacology 22.9 (2000): 729-740.

19. Shabana A., et al. "Cardiovascular benefits of black cumin (Nigella sativa)”. Cardiovascular Toxicology 13.1 (2013): 9-21.

20. Anon. "The cardiovascular actions of the volatile oil of the black seed (Nigella sativa) in rats: elucidation of the mechanism of action". General Pharmacology: The Vascular System 24.5 (1993): 1123-1131.

21. Dollah MA., et al. "Toxicity effect of Nigella sativa on the liver function of rats". Advanced Pharmaceutical Bulletin 3.1 (2013): 97-102.

22. Bioequivalence MOJ. Nigellalogy: A Review on Nigella Sativa 3.6 (2017).

23. Asif HM., et al. "Nigella sativa: Monograph". Journal of Pharmacognosy and Phytochemistry JPP 4.44 (2015): 103-106.

24. Akloul R., et al. Composition and biological activities of the essential oil of Nigella sativa seeds isolated by accelerated microwave steam distillation with cryogenic grinding 1.3 (2014): 23-33. 
25. Suvarna KS., et al. "Bancroft's Theory and Practice of Histological Techniques". 7th ed. Oxford, Churchill Livingstone Elsevier (2013): 654.

26. Dapul H and Laraque D. "Pb Poisoning in Children". Advances in Pediatrics 61.1 (2014): 313-333.

27. Randhawa AM and Ahmed Alenazi S. "Neuropsychiatric Effects of Nigella sativa (Black Seed) - A Review". Alternative and Integrative Medicine 05.01 (2016).

28. Offor SJ., et al. "Pb induced hepato-renal damage in male albino rats and effects of activated charcoal". Frontiers in Pharmacology 8 (2017):1-10.

29. Ahmed MA and Hassanein KMA. Cardio protective effects of Nigella sativa oil on $\mathrm{Pb}$ induced cardio toxicity: Anti inflammatory and antioxidant mechanism 4.5 (2013): 72-80.

30. Radwan RR and Mohamed HA. "Nigella sativa oil modulates the therapeutic efficacy of mesenchymal stem cells against liver injury in irradiated rats". Journal of Photochemistry and Photobiology B: Biology (2018).

\section{Assets from publication with us}

- Prompt Acknowledgement after receiving the article

- Thorough Double blinded peer review

- Rapid Publication

- Issue of Publication Certificate

- High visibility of your Published work

Website: https://www.actascientific.com/

Submit Article: https://www.actascientific.com/submission.php

Email us: editor@actascientific.com

Contact us: +919182824667 